\title{
A statistical model that predicts the length from the left subclavian artery to the celiac axis; towards accurate intra aortic balloon sizing
}

\author{
Haralabos Parissis ${ }^{1 *}$, Alan Soo ${ }^{1}$, Michalis Leotsinidis ${ }^{2}$ and Dimitrios Dougenis ${ }^{3}$
}

\begin{abstract}
Background: Ideally the length of the Intraaortic balloon membrane $(22-27.5 \mathrm{~cm})$ should match to the distance from the left subclavian artery (LSA) to the celiac axis (CA), (LSA - CA). By being able to estimate this distance, better guidance regarding IABP sizing could be recommended.

Methods: Internal aortic lengths and demographic values were collected from a series of 40 cadavers during autopsy. External somatometric measurements were also obtained.

There were 23 males and 17 females. The mean age was $73.1+/-13.11$ years, weight $56.75+/-12.51 \mathrm{~kg}$ and the height $166+/-9.81 \mathrm{~cm}$.

Results: Multiple regression analysis revealed the following predictor variables ( $R 2>0.70)$ for estimating the length from LSA to CA: height (standardized coefficient $(S R C)=0.37, p=0.004)$, age $(S R C=0.35, p<0.001$ ), sex (SRC = $0.21, p=0.088)$ and the distance from the jugular notch to trans-pyloric plane $(S R C=0.61, p<0.001)$.

Recommendations: If LSA-CA $<21.9 \mathrm{~cm}$ use $34 \mathrm{cc} \mathrm{IABP} \mathrm{\&} \mathrm{if} \mathrm{LSA-CA}>26.3 \mathrm{~cm}$ use $50 \mathrm{cc}$ IABP. However if LSA-CA $=21.9-26.3 \mathrm{~cm}$ use $40 \mathrm{cc}$, but be aware that it could be "aortic length-balloon membrane length" mismatching.

Conclusions: Routinely, IABP size selection is being dictated by the patient's height. Inevitably, this leads to pitfalls. We reported a mathematical model of accurate intraaortic balloon sizing, which is easy to be applied and has a high predictive value.
\end{abstract}

\section{Introduction}

The selection of the intraaortic balloon pump (IABP) in adults has been mainly limited to the use of $40 \mathrm{cc}$ and occasionally $34 \mathrm{cc}$ balloon volume, with a membrane length that varies among manufacturers from 22 to 27.5 $\mathrm{cm}$ and an inflated diameter 15 - $18 \mathrm{~mm}$ (Table 1).

Although in a number of clinical cases the $40 \mathrm{cc}$ volume is sufficient, it shall be noted that an increased balloon volume could potentially contributes to morbidity from vascular events and a reduced balloon volume could decrease the beneficial hemodynamic effects for the heart. There is a causal relashionship between the patient's height and balloon trauma. According to Cox et al [1] the balloon size shall be adjusted depending on the patient's height.

\footnotetext{
*Correspondence: hparissis@yahoo.co.uk

'Department of Cardiothoracic Surgery, Royal Victoria Hospital, Belfast, BT12 6BA, UK \& Northern Ireland

Full list of author information is available at the end of the article
}

The ideal balloon for any patient shall be placed at an ideal position, which equals in length the distance from the left subclavian artery to the celiac axis, $90-95 \%$ of the diameter of the descending aorta and equals in volume the blood volume inside the aorta lumen at all given time [2].

Modern treatment guidelines (Table 2) suggest for patients up to $162 \mathrm{~cm}$ high the use of $34 \mathrm{cc}$ balloons, for patients $162-182 \mathrm{~cm}$ high a $40 \mathrm{cc}$ balloon and for patients over $182 \mathrm{~cm}$ high the use of $50 \mathrm{cc}$ balloons. The problem arises when the length of the balloon membrane is greater than the length from the left subclavian artery to the celiac axis. Renal arteries and visceral circulation may potentially be occluded at each inflation of the balloon.

This paper is a pilot study aiming to predict the length of several anatomical lengths in the descending aorta and by extension to lead to the optimum IABP size selection for every individual patient.

\section{Biomed Central}


Table 1 IABP sizes

\begin{tabular}{lll}
\hline Volume & Membrane length & Inflated diameter \\
\hline $34 \mathbf{c c}$ & $21.9(\mathrm{~cm})$ & $14.7(\mathrm{~cm})$ \\
40 & 26.3 & $15-16.2$ \\
50 & 27.5 & 18.3 \\
\hline
\end{tabular}

The main question aims to identify an equation that can calculate the length from the take off of the left subclavian artery to the origin of the celiac axis. The length of the balloon membrane in association with the distance from the left subclavian artery to the take off of the celiac axis will be used as a possible guide to the optimum sizing of the IABP.

\section{Material and methods}

Measurements were carried out from a series of 40 cadavers during autopsy. Twenty-three were male cadavers and 17 female. The mean age was $73.1+/-13.11$ years, mean height was $166+/-9.81 \mathrm{~cm}$ and mean weight was $56.75+/-12.51 \mathrm{~kg}$.

External somatometric measurements were obtained before autopsy (Figure 1a). With intact aortic length, the internal measurements were carried out in situ (Figure $2 a)$. The distance between the origin of the left subclavian artery and the insertion point of the catheter was measured by calculating the length of a guide wire that was introduced to the aortic lumen, from a point $1 \mathrm{~cm}$ below the middle inguinal region to the orifice of the subclavian artery (cross-validated via digital palpation). All other internal measurements were carried out after the anatomical aortic dissection during autopsy (see Table 3, and Table 4).

Our Institutional Review Board approved this study. Individual consents were obtained for all cadaveric examinations and entry into the database.

\section{Statistical Processing}

Statistical analysis was performed with SPSS 17.0 statistical software (SPSS Inc., Chicago, IL, USA). Unpaired student $\mathrm{t}$-test was applied to compare the various measurements between the two genders. Pearson $r$ correlation coefficients were calculated to identify association between variables. Multiple linear regression models were used to predict the sizes of the aorta. The validation of the prediction for the balloon sizing was performed using discriminant analysis. The Cohen's Kappa

Table 2 The current recommendations regarding IABP
sizing
\begin{tabular}{lll}
\hline $\mathbf{3 4} \mathrm{cc}$ & $\mathbf{4 0} \mathrm{cc}$ & $\mathbf{5 0} \mathrm{cc}$ \\
\hline $147-162 \mathrm{~cm}$ & $162-182 \mathrm{~cm}$ & $>182 \mathrm{~cm}$ \\
$\mathrm{BSA}<1.8$ & $\mathrm{BSA}>1.8$ & \\
\hline
\end{tabular}

test was employed to assess the agreement between the selections of the balloon size based on the results of the categorization by using the discriminant analysis model or using the "traditional" categorization (sizing as it is derived by the height of patients). The statistical significant level was set at 0.05

\section{Results}

There have been differences between the two genders with regard to the aortic lengths, with greater differences observed in the distance from the left subclavian artery to the aortic bifurcation. However there have been no differences in the comparison of the internal diameters, between the two genders. (Table 5)

The Table 6 and Figure 2 shows the rates for both genders, depending on the distribution of height. One can see that the majority of males is $162-182 \mathrm{~cm}$ high, whereas females are almost equally divided between (< $162 \mathrm{~cm})$ and $(162-182 \mathrm{~cm})$.

With regards to the differences in the aortic diameter above and below the renal arteries in patients $<162 \mathrm{~cm}$, $162-182 \mathrm{~cm}$ and $>182 \mathrm{~cm}$, a weak association is observed $(r=0.29, p=0.07)$. In addition, this difference in the aortic diameter shows no variance among the three groups or the two genders.

The prediction of intra-aortic diameters was poor $\left(\mathrm{R}^{2}\right.$ $<0.30$ ). However the prediction of the internal measurements by using multiple regression analysis was satisfactory $\left(R^{2}>0.70\right)$ as per Table 7 .

The selection of the balloon size in the traditional methods, depending on the height, shows relatively low consistency (although statistically significant) to the size that would have been selected if the actual length of the internal dimensions of the descending aorta was known. (Consistency test $\mathrm{K}=0.38, \mathrm{p}=0.003$ ).

On the contrary, the selection of the balloon size based on the results of the categorization by using the discriminant analysis model, shows impressive consistency with the sizes that would have been selected based on the actual aortic length $(\mathrm{K}=1, \mathrm{p}<0.001)$.

In order to apply the results of the regression model to predict the length from the left Subclavian artery take off to the Celiac axis (LSA-CA) the following equation is formed:

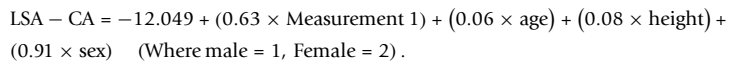

If LSA-CA $<21.9 \mathrm{~cm}$ use $34 \mathrm{cc}$ IABP, LSA-CA = 21.9- $26.3 \mathrm{~cm}$ use $40 \mathrm{cc}$ (may be "aortic length-balloon membrane length" mismatching) \& if LSA-CA > 26.3 $\mathrm{cm}$ use $50 \mathrm{cc}$ IABP.

As far as the depth of the femoral artery is concerned at the inguinal plane, there are no differences between the two genders ( $t$ Test) but there is an 


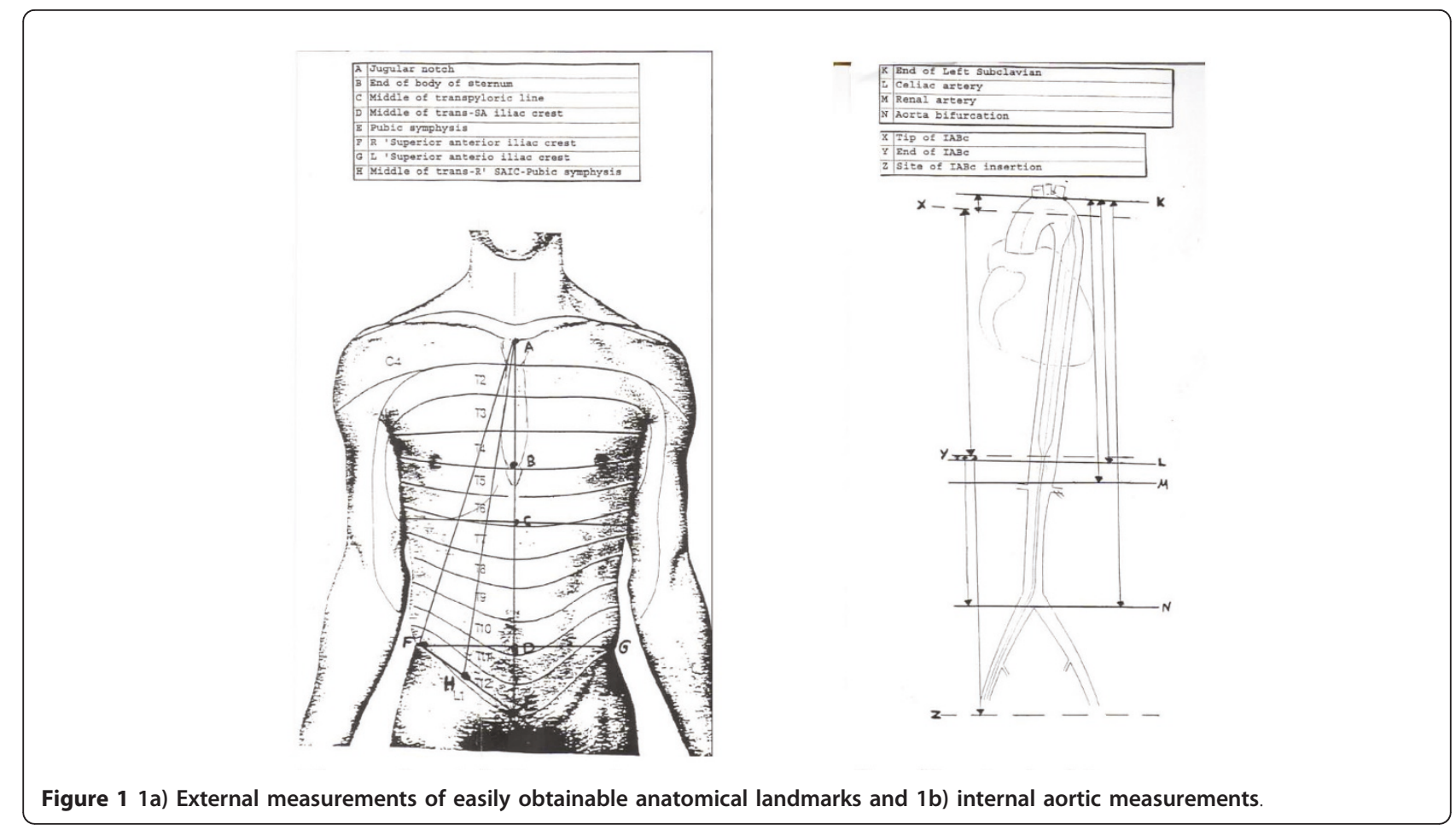

increased association between weight and depth $(\mathrm{r}=$ $0.49, \mathrm{p}=0.002$ ).

\section{Discussion}

The efficiency of the IABP depends on multiple factors, which include: The ability of the ejection system to

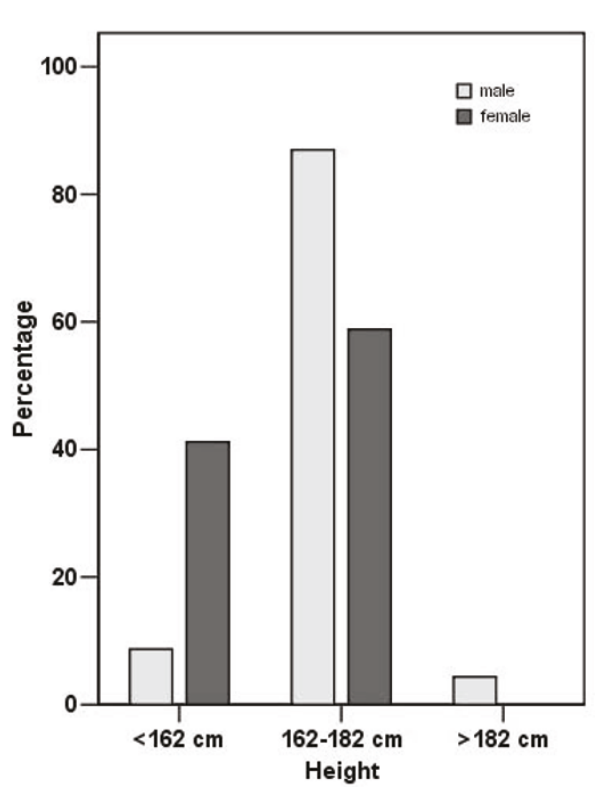

Figure 2 Graphic representation of the height distribution between genders. trace electrical stimulation events and transfer the gas during every cardiac cycle, the patient's hemodynamic status, the anatomical position of the balloon and lastly the volume of the selected balloon.

The variables that affect the size and duration of the IABP inflation with gas and consequently the diastolic increase in pressure, were first published 20 years ago, in an innovative study by Weber et al [3]. They reported that the arterial pressure has direct impact on the balloon performance and that the beneficial effects of the IABP reduces when arterial pressure increases.

The heart rate also affects the balloon functioning. The faster the heart rate, the less the balloon inflation time and the diastolic augmentation.

The relation between the aortic pressure and the volume of the aorta reflects the aortic elasticity and the reduced aortic elasticity means reduced diastolic augmentation.

The closer the IABP to the aortic valve, the higher is the incremented diastolic augmentation [4].

The effect of the IABP diameter to the patient's hemodynamics was studied by Weber, Janicki, and Walker [3]. They concluded that for any given arterial pressure or aortic size, the greatest augmentation in mean aortic diastolic pressure was achieved with complete occlusion. It is obvious that in $100 \%$ occlusion of the aortic lumen, a lesion to the aortic wall and erythrocytes could possibly occur and thus the ideal convergence is thought to be approximetly 90 to $95 \%$. 
Table 3 Row data and measurements depicted in Figure 1

\begin{tabular}{|c|c|c|c|c|c|c|c|c|c|c|c|c|c|c|c|c|c|c|}
\hline \multicolumn{6}{|c|}{ Demographics } & \multicolumn{8}{|c|}{ External Lengths $(\mathrm{cm})$ Diameters } & \multicolumn{4}{|c|}{ Internal Lengths } & \multirow{2}{*}{$\frac{\text { Depth }}{\text { Dpth }}$} \\
\hline $\mathrm{Pt}$ & Hght & Wght & Age & SEX & BSA & Meas1 & Meas2 & Meas3 & Meas4 & Meas5 & Dthrax & Dren & Dbifrc & $\begin{array}{c}\text { LSA- } \\
\text { CA }\end{array}$ & $\begin{array}{l}\text { LSA- } \\
\text { Ren }\end{array}$ & $\begin{array}{l}\text { LSA- } \\
\text { Bifr }\end{array}$ & $\begin{array}{l}\text { LSA- } \\
\text { Insr }\end{array}$ & \\
\hline 1 & 168 & 55 & 89 & $\mathrm{~m}$ & 1.62 & 26 & 45 & 24.25 & 43.25 & 49 & 30 & 29 & 25 & 22.5 & 27.5 & 37.5 & 53 & 2.5 \\
\hline 2 & 178 & 71 & 76 & $\mathrm{~m}$ & 1.88 & 29.5 & 53.1 & 27.4 & 51 & 58.2 & 29 & 28 & 24 & 26 & 27.6 & 36 & 52 & 2.3 \\
\hline 3 & 148 & 47 & 84 & f & 1.38 & 25.5 & 44.5 & 23.25 & 42.25 & 49 & 31 & 26 & 21 & 22.5 & 25 & 32.5 & 50.5 & 2.2 \\
\hline 4 & 143.5 & 41 & 79 & f & 1.28 & 21.5 & 44 & 19.45 & 41.95 & 49.4 & 28 & 23 & 20 & 19.5 & 21.4 & 31 & 48.5 & 2.4 \\
\hline 5 & 165 & 55 & 89 & f & 1.60 & 26 & 44 & 24.05 & 42.55 & 50.5 & 27 & 25 & 20 & 23 & 26 & 36.5 & 53.5 & 2.1 \\
\hline 6 & 163 & 46 & 34 & f & 1.47 & 26.5 & 49 & 24.6 & 47.6 & 51 & 21 & 20 & 17 & 20.5 & 23.4 & 32.2 & 51 & 2.1 \\
\hline 7 & 153 & 63 & 52 & f & 1.60 & 27.5 & 50 & 25.3 & 47.8 & 53 & 24 & 21 & 18 & 24 & 27 & 34 & 49.5 & 2.9 \\
\hline 8 & 185 & 50 & 77 & $\mathrm{~m}$ & 1.67 & 27 & 47 & 24.6 & 44.6 & 51.5 & 32 & 30 & 26 & 27 & 29.5 & 41 & 57.8 & 1.8 \\
\hline 9 & 165 & 50 & 73 & $\mathrm{~m}$ & 1.53 & 28.5 & 50.7 & 26.65 & 48.85 & 52 & 23 & 21 & 17 & 23 & 25 & 38 & 51 & 2.1 \\
\hline 10 & 163 & 41 & 56 & f & 1.40 & 22 & 40 & 20.35 & 38.35 & 42.3 & 18 & 17 & 13 & 20 & 23 & 33 & 47 & 1.8 \\
\hline 11 & 173 & 45 & 83 & f & 1.52 & 26.5 & 47 & 24.75 & 45.25 & 48 & 23 & 21 & 18 & 26 & 29 & 41 & 56.5 & 2.0 \\
\hline 12 & 165 & 66 & 68 & $f$ & 1.73 & 25 & 43 & 23.5 & 41.5 & 45.6 & 27 & 24 & 19 & 24.5 & 28 & 38.5 & 52.6 & 2.5 \\
\hline 13 & 173 & 63 & 60 & f & 1.75 & 26 & 46.5 & 24 & 44.5 & 49.5 & 29 & 26 & 21 & 23 & 26.5 & 37.6 & 53.2 & 2.4 \\
\hline 14 & 175 & 64 & 58 & $f$ & 1.78 & 26.5 & 50.5 & 24.25 & 48.25 & 53.8 & 28.5 & 27 & 20 & 24.5 & 27.5 & 37.7 & 54.3 & 2.6 \\
\hline 15 & 170 & 55 & 74 & f & 1.63 & 26 & 48 & 24 & 46 & 52.5 & 26 & 24.5 & 19.5 & 25 & 28.7 & 36.6 & 53.6 & 2.3 \\
\hline 16 & 175 & 63 & 74 & $\mathrm{~m}$ & 1.77 & 27.5 & 49 & 25 & 46.5 & 53.7 & 24 & 22.5 & 18 & 22 & 26.8 & 38.8 & 51.5 & 1.8 \\
\hline 17 & 173 & 64 & 94 & $\mathrm{~m}$ & 1.76 & 26.5 & 46 & 24.5 & 44 & 49.5 & 25.5 & 23 & 17.5 & 23.5 & 25.5 & 36.2 & 50.7 & 2.0 \\
\hline 18 & 180 & 64 & 76 & $\mathrm{~m}$ & 1.82 & 25 & 44.5 & 23 & 42.5 & 50.6 & 24 & 22.5 & 18 & 24 & 27.8 & 38.3 & 56.5 & 1.6 \\
\hline 19 & 153 & 54 & 42 & $f$ & 1.50 & 25.5 & 46 & 23.75 & 44.25 & 49.8 & 26 & 24.5 & 19 & 20.5 & 23.3 & 31.5 & 47.8 & 2.1 \\
\hline 20 & 173 & 84 & 70 & $\mathrm{~m}$ & 1.98 & 31 & 52 & 28.1 & 49.1 & 56.2 & 28 & 27 & 19.5 & 29 & 31.5 & 40.7 & 55.9 & 3.1 \\
\hline 21 & 179 & 78 & 71 & $\mathrm{~m}$ & 1.97 & 29.5 & 51 & 27.25 & 48.75 & 56.7 & 29 & 27.5 & 20.5 & 28 & 32 & 42.9 & 58.1 & 2.3 \\
\hline 22 & 180 & 98 & 74 & $\mathrm{~m}$ & 2.18 & 31 & 51.5 & 28.5 & 49 & 55.8 & 28.5 & 26.5 & 18.5 & 27 & 31.8 & 43.7 & 59.6 & 3.3 \\
\hline 23 & 178 & 55 & 73 & $\mathrm{~m}$ & 1.69 & 27.5 & 48.5 & 24.75 & 45.75 & 53.9 & 24 & 23 & 17 & 25.5 & 29.7 & 41.8 & 58.7 & 2.1 \\
\hline 24 & 163 & 64 & 83 & $\mathrm{~m}$ & 1.69 & 28.5 & 49 & 25.75 & 46.25 & 52.8 & 27 & 25.5 & 18.5 & 23 & 26.9 & 35.8 & 52.6 & 2.6 \\
\hline 25 & 163 & 43 & 75 & f & 1.43 & 25.5 & 44.5 & 23.85 & 42.85 & 48.2 & 23 & 21 & & 23 & 26.5 & 35.7 & 50.8 & 1.7 \\
\hline 26 & 158 & 40 & 57 & $\mathrm{~m}$ & 1.35 & 24.5 & 42 & 22.75 & 40.25 & 45.6 & 22 & 20.5 & 14.5 & 20 & 23.6 & 30.9 & 46.6 & 1.8 \\
\hline 27 & 178 & 72 & 69 & $\mathrm{~m}$ & 1.89 & 27 & 46.5 & 24.75 & 44.25 & 51.2 & 24 & 21 & 15.5 & 24 & 28.3 & 39 & 56.8 & 1.9 \\
\hline 28 & 163 & 56 & 63 & $\mathrm{~m}$ & 1.60 & 26 & 45 & 24.25 & 43.25 & 49.2 & 23.5 & 22 & 16 & 23 & 26.8 & 36.1 & 50.4 & 2.0 \\
\hline 29 & 170 & 46 & 84 & $\mathrm{~m}$ & 1.51 & 25.5 & 43.5 & 23.25 & 41.25 & 47.4 & 25 & 23.5 & 17 & 24 & 28.1 & 38.8 & 53.9 & 1.6 \\
\hline 30 & 180 & 57 & 73 & $\mathrm{~m}$ & 1.73 & 27 & 49 & 24.25 & 46.25 & 54.6 & 27 & 25 & 18.5 & 25 & 29.6 & 42.3 & 57.7 & 1.7 \\
\hline 31 & 155 & 55 & 76 & $\mathrm{f}$ & 1.53 & 24.5 & 45.5 & 22.25 & 43.25 & 48.7 & 24.5 & 22.5 & 19 & 23 & 26.2 & 33.1 & 48.3 & 1.9 \\
\hline 32 & 156 & 54 & 71 & f & 1.52 & 24 & 43.5 & 21.75 & 41.25 & 46.5 & 23.5 & 22.5 & 17.5 & 22 & 25.3 & 32.4 & 49.1 & 1.8 \\
\hline 33 & 153 & 42 & 93 & f & 1.35 & 21.5 & 42.4 & 19.75 & 40.65 & 46.2 & 22 & 20.5 & 15.5 & 21.5 & 24.8 & 31.3 & 47.9 & 1.5 \\
\hline 34 & 165 & 55 & 87 & $\mathrm{~m}$ & 1.60 & 26.5 & 49.5 & 24 & 47 & 52.9 & 27.5 & 25 & 19.5 & 26 & 28.5 & 37.2 & 51.8 & 1.8 \\
\hline 35 & 175 & 66 & 73 & $\mathrm{~m}$ & 1.80 & 28 & 47 & 25.25 & 44.25 & 52.1 & 26 & 24.5 & 18 & 24 & 28.9 & 38.1 & 54.1 & 1.5 \\
\hline 36 & 163 & 40 & 90 & $\mathrm{~m}$ & 1.38 & 26.5 & 44 & 24.25 & 41.75 & 48.2 & 24.5 & 22 & 17.5 & 26 & 28.1 & 37.4 & 50.9 & 1.3 \\
\hline 37 & 163 & 62 & 88 & $\mathrm{~m}$ & 1.67 & 25 & 46.5 & 22.75 & 44.25 & 49.6 & 28.5 & 27 & 20 & 24 & 27.8 & 36.9 & 51.6 & 1.9 \\
\hline 38 & 165 & 49 & 69 & f & 1.52 & 24.5 & 43.5 & 22.75 & 41.75 & 47.7 & 26 & 24.5 & 18.5 & 23 & 27.1 & 36.1 & 50.2 & 1.7 \\
\hline 39 & 165 & 47 & 80 & $\mathrm{~m}$ & 1.50 & 25 & 44 & 23 & 42 & 48.4 & 25.5 & 23.5 & 16.5 & 23 & 26.9 & 35.3 & 51.1 & 1.5 \\
\hline 40 & 158 & 50 & 67 & $\mathrm{~m}$ & 1.49 & 25 & 45.5 & 22.75 & 43.25 & 48 & 26 & 24.5 & 17.5 & 22 & 25.6 & 34.2 & 49.9 & 1.7 \\
\hline
\end{tabular}

(The Trans-pyloric plane is located halfway between the jugular notch and the upper border of the pubic symphysis);

The balloon volume shall be at least $50 \%$ of the stroke volume. In a hypothetical patient with poor cardiac index, the rate of the diastolic incrementation to support an insufficient heart is limited because of the fact that the stroke volume in the given patient is low and thus the ideal balloon volume shall be low. In the course of improvement of the hypothetical $s$ patient $s$ hemodynamics and the more the stroke volume improves, which means that the volume of blood transferred within the aorta at every stroke increases, then the balloon volume of the IABP, necessary to maintain the same level of diastolic augmentation, increments. This fact may suggest that during a period of time from the balloon implantation till the successful removal of 
Table 4 Definitions of the variables analysed in table 3 (eg. Measurements, Diameters, lengths between various aortic branches)

\begin{tabular}{|c|c|c|c|}
\hline $\begin{array}{l}\text { Measurement } \\
1\end{array}$ & from the jugular notch to the trans-pyloric plane & $\begin{array}{l}\text { LSA- } \\
\text { CA }\end{array}$ & from the left subclavian take off to the celiac axis \\
\hline $\begin{array}{l}\text { Measurement } \\
2\end{array}$ & from the jugular notch to the anterior superior iliac spine & $\begin{array}{l}\text { LSA- } \\
\text { Renal }\end{array}$ & from the left subclavian take off to the renal artery \\
\hline $\begin{array}{l}\text { Measurement } \\
3\end{array}$ & $\begin{array}{l}\text { from the middle point between the jugular } \\
\text { notch and the sternal angle to the } \\
\text { trans-pyloric plane }\end{array}$ & $\begin{array}{l}\text { LSA- } \\
\text { Bifur }\end{array}$ & $\begin{array}{l}\text { from the left subclavian take off } \\
\text { to the aortic bifurcation }\end{array}$ \\
\hline $\begin{array}{l}\text { Measurement } \\
4\end{array}$ & $\begin{array}{l}\text { from the middle point between the jugular notch and the } \\
\text { sternal angle to the anterior superior iliac spine. }\end{array}$ & $\begin{array}{l}\text { LSA- } \\
\text { Inser }\end{array}$ & $\begin{array}{l}\text { from the left subclavian artery take off to the IAB } \\
\text { insertion } 2 \mathrm{~cm} \text { below the mid-inguinal ligament }\end{array}$ \\
\hline $\begin{array}{l}\text { Measurement } \\
5\end{array}$ & $\begin{array}{l}\text { from the jugular notch to the middle point in the line between } \\
\text { the anterior superior iliac spine and symphysis pubis }\end{array}$ & Depth & $\begin{array}{l}\text { the depth of the femoral artery from the surface of the } \\
\text { skin, } 2 \mathrm{~cm} \text { below the mid-inguinal ligament }\end{array}$ \\
\hline Dthorax & Aortic diameter (at the middle of the thorax) & & \\
\hline Drenal & Aortic diameter (at a renal level) & & \\
\hline Dbifurc & Aortic diameter (bifurcation level) & & \\
\hline
\end{tabular}

the balloon, the performance of corrective interventions to the balloon volume by intervals, based on the patient's clinical status, may be the proper method in order to provide ideal diastolic augmentation, both for the insufficient heart and the heart that shows improvement.

To summarize up to now, the optimum balloon sizing shall be accompanied by adjustments of the balloon size and volume, which shall correspond to the different hemodynamic scenarios.

The equation to calculate the ideal balloon size for every individual patient, shall take into account the patient's hemodynamic state (Arterial pressure, Heart

Table 5 Gender comparison of external measurements, aortic lengths and diameters

\begin{tabular}{lcccc}
\hline & \multicolumn{2}{c}{ male $(\mathbf{n}=\mathbf{2 3})$} & \multicolumn{2}{c}{ female $(\mathbf{n}=\mathbf{1 7})$} \\
& mean & S.D & mean & S.D \\
\hline Height $(\mathrm{cm})^{*}$ & 171.09 & 7.98 & 160.97 & 9.20 \\
Weight* $^{*}$ & 60.30 & 13.93 & 51.94 & 8.51 \\
BSA $^{*}$ & 1.70 & 0.20 & 1.28 & 0.14 \\
BMI & 20.50 & 3.93 & 20.10 & 3.25 \\
Age & 76.57 & 9.15 & 68.41 & 16.24 \\
Measur1* & 27.11 & 1.88 & 24.97 & 1.80 \\
Measur2* & 47.38 & 3.03 & 45.41 & 2.83 \\
Measur3* & 24.83 & 1.72 & 23.04 & 1.76 \\
Measur4 & 45.10 & 2.88 & 43.53 & 2.75 \\
Measur5* & 51.61 & 3.31 & 48.92 & 2.88 \\
Dthorax & 26.24 & 2.53 & 25.15 & 3.25 \\
Drenal & 24.52 & 2.67 & 22.94 & 2.62 \\
Dbifurc & 18.70 & 2.88 & 18.38 & 2.06 \\
LSA-CA* $^{*}$ & 24.41 & 2.14 & 22.68 & 1.84 \\
LSA-Rena* $^{*}$ & 27.99 & 2.11 & 25.81 & 2.12 \\
LSA-Bifur* & 38.13 & 3.00 & 34.75 & 2.95 \\
LSA-Inser* $^{*}$ & 53.57 & 3.43 & 50.84 & 2.71 \\
Depth & 2.01 & 0.49 & 2.12 & 0.37 \\
\hline *p<0.05 (t-test) & & & &
\end{tabular}

supply, pulses/min) as well as the measurements of the aortic length and diameter from the subclavian artery take off to the celiac axis.

Wiekel et al [5] after studying the aortographies of 169 patients, concluded that the corrected mid-thoracic diameters varied in size from 16 to $30 \mathrm{~mm}$ with $90 \%$ of the patients having a diameter over $19 \mathrm{~mm}$. This has been possibly taken into consideration by the manufacturers and thus the balloon diastolic diameter is between $14.7 \mathrm{~mm}$ and $18.5 \mathrm{~mm}$.

We reached the same conclusions in our measurements regarding the mid-thoracic diameters.

Paulin et al [6] suggested that the aorta's size is related to the patient's height, age and weight. After studying a series of aortic diameters, he suggested that the ascending aorta has a relatively fixed lumen, which varies from 22 to $38 \mathrm{~mm}$ in adults. The descending aorta has a slightly smaller lumen than the ascending aorta. In addition, the aorta's diameter narrows down after the renal artery take off.

In our measurements regarding the correlation between the difference of the aortic diameter above and below the renal arteries and the patients' height, a weak association resulted. In addition, this difference in the aortic diameter shows no variance between the two genders.

The balloon distal edge shall be "proximal" to the renal arteries' take off, so as to avoid occluding the renal arterial circulation. Swartz et al [7] studied the arterial dysfunction of the kidneys as a result of the position of the IABP on the take off of the renal arteries.

Table 6 Height distribution between genders

\begin{tabular}{lll}
\hline Height & male (\%) & fem (\%) \\
\hline$<162 \mathrm{~cm}$ & 8.7 & 41.2 \\
$162-182 \mathrm{~cm}$ & 87.0 & 58.8 \\
$>182 \mathrm{~cm}$ & 4.3 & \\
\hline
\end{tabular}


Table 7 Multiple regression model

\begin{tabular}{llccc}
\hline & Predictor variables & URC & SRC & $\mathbf{p}^{*}$ \\
\hline LSA-CA & Height & 0.08 & 0.37 & 0.004 \\
$\mathrm{R}^{2}=0.71$ & Age & 0.06 & 0.35 & $<0.001$ \\
& ${ }^{\mp}$ Gender & 0.91 & 0.21 & 0.088 \\
& Measurement 1 & 0.63 & 0.61 & $<0.001$ \\
& Constant & -12.05 & - & 0.021 \\
\hline LSA-RENAL & Height & 0.11 & 0.45 & $<0.001$ \\
$\mathrm{R}^{2}=0.70$ & Age & 0.04 & 0.24 & 0.001 \\
& Measurement 1 & 0.48 & 0.43 & $<0.001$ \\
& Constant & -6.90 & - & 0.077 \\
\hline LSA-BIF & Height & 0.23 & 0.66 & $<0.001$ \\
$\mathrm{R}^{2}=0.81$ & Age & 0.05 & 0.19 & 0.017 \\
& Measurement 1 & 0.46 & 0.28 & 0.005 \\
& Constant & -16.99 & - & $<0.001$ \\
\hline LSA-INS & Height & 0.25 & 0.71 & $<0.001$ \\
$\mathrm{R}^{2}=0.71$ & Measurement 5 & 0.23 & 0.23 & 0.029 \\
& Constant & -0.63 & - & 0.029 \\
\hline
\end{tabular}

$\left(R^{2}>0.70\right)$

URC: Unstandardized coefficient

SRC: Standardized coefficient

*Only the coefficients with a $p<0.10$ are presented

${ }^{\mp}$ male $=1$, female $=2$

He concluded that such a position of the balloon causes renal ischemia.

In our paper it became apparent that the female population consists of smaller dimensions of skeleton. The mean LSA-CA distance was found to be 22.68 $+/-1.84$. In such a population, even a $34 \mathrm{CC}$ IAB would lie below the take off of the renal arteries, with subsequent «aortic-device mismatch» and negative consequences.

During our study the traditional balloon sizing, based only on the patients height, shows relatively low consistency to the size that would have been selected if the actual length of the internal dimensions of the descending aorta was known. A report by Rastan et al [8] using CT scans identified IABP malpositions to be a common finding. Anatomic to balloon length mishmatch was found in $68.2 \%$ of the cases, with subsequently severe adverse effects.

Yosioka et al [9] reported that aortic-balloon mismatch could cause abdominal arterial branch obstruction. However, clinical reports of intra-abdominal ischemia due to anatomic-to-device length mismatch are limited [10,11]. Furthermore, Cho et al [12] has published in a CT study a $29 \%$ rate of renal artery compromise in patient heights of 163 to $183 \mathrm{~cm}$ when using a 40-mL balloon size, especially in patients with a small stature. In our study, we confirm by enlarge, these findings: there is only a varying correlation between height and aortic length, which is influenced by age, sex, and possibly ethnic differences [12].
According to Alexander et al [13] the rate of the patients over 70 years old that undergo heart interventions, has raised from $7-9 \%$ in the 1980's to over $30 \%$ in the 2000's. The number of women in need of cardiac interventions has increased from 31\% in 1982 to over $40 \%$ today. Moreover, a $3-5 \%$ of the patients currently live their eighth decade. Sisto et al [14] mention that an increased number of patients living their eighth decade and who are in need of an IABP support.

Taking into account that that mean age of patients that need a heart operation rises (and the age increases the risk of aortic atherosclerotic disease) and the increasing rate of the women patients population (having smaller aortic diameter) which need an IABP, one would conclude that a more meticulous size selection is required under such clinical conditions, otherwise the aortic environment could be hiding potential risks. Moreover, Wolvek et al [15] reported that 35.7\% of female patients fall into the category of less than 62 in. where the aortic diameter narrows down from $20 \mathrm{~mm}$ over the renal arteries to $13 \mathrm{~mm}$ below the renal arteries. In such patients, a large IABP size is problematic since 5-6 cm of the IABP fills the "normally narrowed" part of the abdominal aorta (aortic-device mismatch).

The population that we studied was $72.8 \%$ male and $27.2 \%$ female. The average height of women was 160.97 cm. A $41.2 \%$ were less than $162 \mathrm{~cm}$ high. Contrary to other studies, our measurements did not reveal a great aortic physiological narrowing of the aorta below the renal arteries.

The aortic measurements in our study are related to the height of the patients and other somatometric measurements (age, sex, external measurement of the thoracic cage). Neither weight nor BSA affect the aortic length or diameter.

In our measurements, the depth of the femoral artery at the inguinal region did not differ between the two genders, though it was proportionate to the body weight.

The possible limitations of the study are related to the relative small number of subjects studied, the fact that most aortas were not atheromatic, so no corkscrew effects or angulations were present and lastly the relative small number of patients over $182 \mathrm{~cm}$ high.

Concluding, the guidelines according to which the appropriate size of the intra-aortic balloons are selected, are based on the estmation of the LSA-CA taking into consideration the patients height, age, sex and the easily obtainable distance from the jugular notch to "halfway between the jugular notch and the upper border of the pubic symphysis»; so if LSA-CA is $<21.09 \mathrm{~cm}$ use $34 \mathrm{cc}$ IABP, 21.9-26.3 cm use $40 \mathrm{cc}$, 
but prepare for «aortic-device» mismatching and if > $26.3 \mathrm{~cm}$ use $50 \mathrm{cc}$.

\section{Author details}

'Department of Cardiothoracic Surgery, Royal Victoria Hospital, Belfast, BT12 $6 \mathrm{BA}$, UK \& Northern Ireland. 'Department of Statistics \& Epedemiology University of Patras Medical School, Patras, 26504, Greece. ${ }^{3}$ Cardiothoracic Department University of Patras Medical School, Patras, 26504, Greece.

\section{Authors' contributions}

HP conceived of the idea, carried out all the measurements and wrote the manuscript. AS helped in organizing the data and also helped in the process of writing the manuscript. ML carried out the statistical analysis. DD supervised the project and offer valuable points and ideas. All authors read and approved the final manuscript.

\section{Competing interests}

The authors declare that they have no competing interests.

Received: 4 May 2011 Accepted: 9 August 2011

Published: 9 August 2011

\section{References}

1. Cox P, Kellett M, Goran S, Morton J, Wolvek S: Plaque abrasion and Intraaortic Balloon Leak. Chest 1995, 108(6):1495-98.

2. Kantrowitz A: Origins of intraaortic balloon pumping. Ann Thorac Surg 1990, 50(4):672-4.

3. Weber KT, Janicki JS: Intra-aortic balloon counterpulsation. A review of physiological principles, clinical results and device safety. Ann Thorac Surg 1974, 17(6):602-36.

4. Gundel WD, Brown BG, Gott VL: Coronary collateral flow studies during variable aortic root pressure waveforms. J Appl Physiol 1970, 29(5):579-86.

5. Weikel AM, Jones RT, Dinsmore R, Petschek HE: Size limits and pumping effectiveness of intra-aortic balloons. Ann Thorac Surg 1971, 12(1):45-53.

6. Paulin S: Aortography. In Cardiac catheterisation, angiography and intervention, Philadelphia. Edited by: Grossman W, Baim D. Lea 1991:.

7. Swartz MT, Sakamoto T, Arai H, Reedy JE, Salenas L, Yuda T, et al: Effects of intraaortic balloon position on renal artery blood flow. Ann Thorac Surg 1992, 53(4):604-10.

8. Rastan A, Tillmann E, Subramanian S, Lehmkuhl L, Funkat A, Leontyev S, et al: Visceral Arterial Compromise During Intra-Aortic Balloon Counterpulsation Therapy. Circulation 2010, 122 (11 suppl):S92-S99.

9. Yoshioka Y, Saitoh K, Kubo E, Kitamura M, Nishida H, Endoh M, et al: A new IABP balloon for Japanese to prevent the abdominal complication. Kyobu Geka 1987, 40(9):736-742.

10. Shin H, Yozu R, Sumida T, Kawada S: Acute ischemic hepatic failure resulting from intraaortic balloon pump malposition. Eur J Cardiothorac Surg 2000, 17(4):492-494.

11. Haga M, Sasajima T, Asada H, Azuma N, Morimoto N, Kubo Y: Extensive bowel infarction caused by intraaortic balloon pumping. Nippon Kyobu Geka Gakkai Zasshi 1993, 41(1):93-96.

12. Cho YS, Lim C, Han MJ, Chun EJ, Choi SI, Park KH, et al: Should we consider the ethnic difference in selecting size of intraaortic balloon by commercial guideline? ASAIO J 2009, 55(5):519-522.

13. Alexander KP, Anstrom KJ, Muhlbaier LH, Grosswald RD, Smith PK, Jones RH, Peterson ED: Outcomes of cardiac surgery in patients > or $=80$ years: results from the National Cardiovascular Network. J Am Coll Cardiol 2000, 35(3):731-738.

14. Sisto DA, Hoffman DM, Fernandes S, Frater RW: Is Use of Intraaortic Balloon Pump in Octogenarians justified? Ann Thorac Surg 1992, 54(3):507-11.

15. Wolvek S: The hostile environment of the aging human aorta and the smaller patient-their implications for the intrapaortic balloon. Perfusion 1994, 9(2):87-94.

\section{doi:10.1186/1749-8090-6-95}

Cite this article as: Parissis et al:: A statistical model that predicts the length from the left subclavian artery to the celiac axis; towards accurate intra aortic balloon sizing. Journal of Cardiothoracic Surgery 2011 6:95.

\section{Submit your next manuscript to BioMed Central and take full advantage of:}

- Convenient online submission

- Thorough peer review

- No space constraints or color figure charges

- Immediate publication on acceptance

- Inclusion in PubMed, CAS, Scopus and Google Scholar

- Research which is freely available for redistribution

Submit your manuscript at www.biomedcentral.com/submit
C Biomed Central 